\title{
Patient-specific, 3-dimensionally engineered silicone Y-stents in tracheobronchomalacia: Clinical experience with a novel type of airway stent
}

Thomas Schweiger, MD, PhD, ${ }^{\mathrm{a}}$ Thomas R. Gildea, MD, MS, FCCP, ${ }^{\mathrm{b}}$ Helmut Prosch, MD, György Lang, MD, PhD, ${ }^{a}$ Walter Klepetko, $\mathrm{MD},{ }^{\mathrm{a}}$ and Konrad Hoetzenecker, $\mathrm{MD}, \mathrm{PhD}^{\mathrm{a}}$ Vienna, Austria, and Cleveland, Ohio

\footnotetext{
From the ${ }^{\mathrm{a} D i v i s i o n}$ of Thoracic Surgery, and ${ }^{\mathrm{c}}$ Department of Biomedical Imaging and Image-Guided Therapy, Medical University of Vienna, Vienna, Austria; and ${ }^{\mathrm{b}}$ Department of Pulmonary, Allergy and Critical Care Medicine, Respiratory Institute, Cleveland Clinic Foundation, Cleveland, Ohio.

Supported by NIH-NCAI grant \#1U54HC119810-03 to T.R.G. All other authors received no support.

Disclosures: T.R.G. is the inventor of the stent and an employee of Cleveland Clinic. Cleveland Clinic and Cleveland Clinic Institutional Officials/Leaders have an equity interest in Custom Orthopaedic Solutions and are entitled to royalty payments from the company for technology developed at Cleveland Clinic. Custom Orthopaedic Solutions is the manufacturer of the stents. T.R.G. provided scientific advice during stent design and the production process but did not interfere with the clinical management of the patients or with treatment decisions. All other authors have nothing to disclose with regard to commercial support.

Received for publication April 10, 2018; revisions received May 31, 2018; accepted for publication June 14, 2018; available ahead of print Aug 10, 2018.

Address for reprints: Konrad Hoetzenecker, MD, PhD, Medical University of Vienna-Thoracic Surgery, Waehringer Guertel 18-20, 1090 Vienna, Austria (E-mail: konrad.hoetzenecker@meduniwien.ac.at).

J Thorac Cardiovasc Surg 2018;156:2019-21

$0022-5223 / \$ 36.00$

Copyright (ㄷ 2018 by The American Association for Thoracic Surgery

https://doi.org/10.1016/j.jtcvs.2018.06.049
}

Video clip is available online.

Airway stents are routinely used for the treatment of various diseases of the central airways. To achieve the best possible alignment with the airway, stents are available in numerous dimensions, varying in diameter and length. In most cases, good results with significant relief of symptoms can be achieved with off-the-shelf stents. In some cases, however, the available stents cannot be used because of excessively enlarged airways, unusual branching angles, or airway distortion.

Despite the substantial legal hurdles that have to be overcome before their clinical use, 3-dimensional (3D) modeling and printing applications in medicine are increasingly reported. ${ }^{1}$ The advantage of an airway stent designed and produced for an individual patient is that a perfect alignment with the mucosa can be achieved. This could decrease typical stent-related complications, such as biofilm formation and mucus retention between the airway and the stent, formation of granulation tissue, and stent migration. Experience, however, is limited to preclinical studies. $^{2}$ We herein report the first 2 European clinical applications of customized silicone Y-stents, which were manufactured with 3D-printing technology.

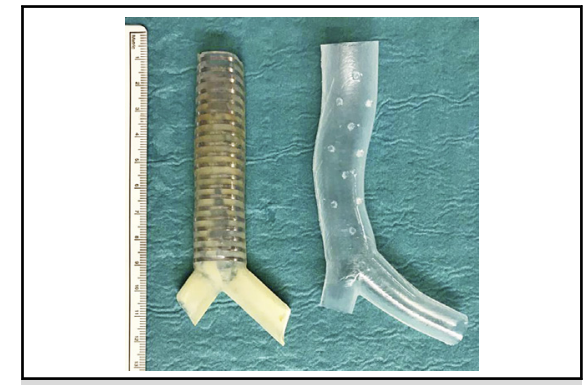

Conventional dynamic Y-stent (left) and patientspecific, 3D-molded Y-stent (right).

Central Message

Patient-specific, 3D-engineered silicone stents were manufactured and successfully implanted in 2 patients with tracheobronchomalacia.

See Editorial Commentary page 2022.

\section{PATIENTS AND METHODS}

The first patient was a 69-year-old man with severe tracheobronchomalacia. He had undergone tracheobronchoplasty with posterior mesh stabilization of the trachea and both main bronchi 4 years previously; however, that surgery resulted in only temporary relief. The patient's condition deteriorated gradually, and he presented again with a request for treatment Reevaluation of the patient included dynamic bronchoscopy and dynamic computed tomography. Stenting with conventional stents was not expected to be successful because of the dimensions of his central airways (largest diameter was $32 \mathrm{~mm}$ ). A patient-specific silicone Y-stent was manufactured (Figure 1). To obtain an optimal size match, a virtual prototype was designed on the basis of 3D reconstructed computed tomographic imaging data (Video 1). In a second step, the stent was manufactured by 3D printing a mold and injecting medical-grade silicone into this mold (Custom Orthopedics, Cleveland, Ohio, in cooperation with Novatech SA, La Ciotat, France). The maximum outer diameter of the tracheal part of the stent was $27 \mathrm{~mm}$, with $2 \mathrm{~mm}$ wall thickness. The stent was implanted by direct laryngoscopy with rigid forceps and 2 Cook catheters as guidance. The alignment of the stent with the mucosal lining was perfect. At the last follow-up 8 months after stenting, the patient has had sustained relief of symptoms to his highest satisfaction. The patient has started to participate actively in life again.

Similar to the first case, a 71-year-old male patient with tracheobronchomalacia and excessive dynamic airway collapse was admitted to our department. The patient had undergone tracheobronchoplasty with posterior stabilization 1.5 years previously. The condition of the patient improved after surgery, and the relief of symptoms was sustained for 1 year but gradually deteriorated after that point. Because the patient had notable symptoms, he received a 15-mm Dynamic Y-Stent (Boston 


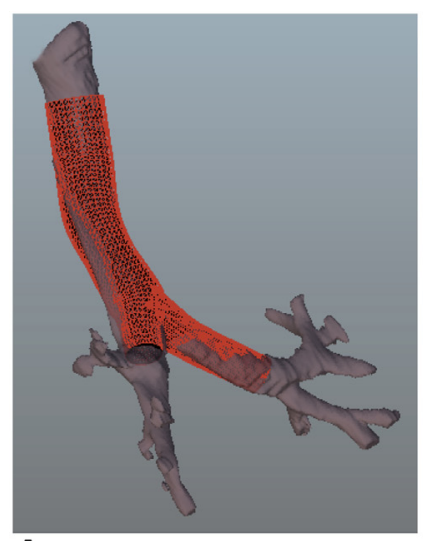

A

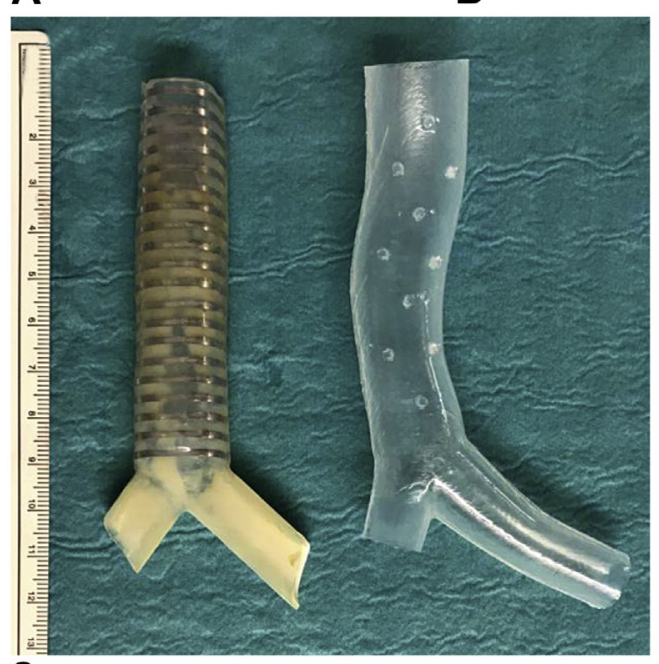

C

B
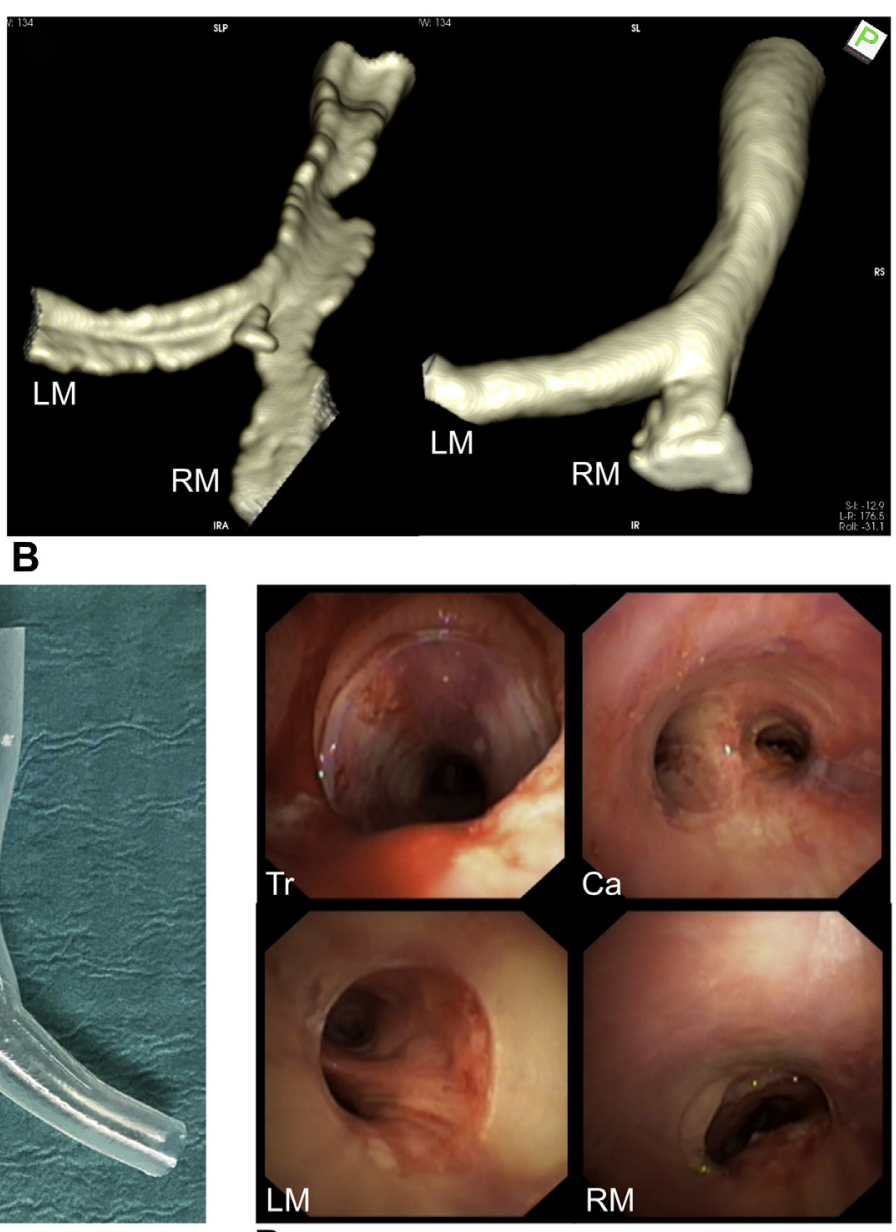

D

FIGURE 1. A, Three-dimensional model showing the central airways of patient 2 and the outer diameter of the customized stent (red). B, Three-dimensional reconstruction of dynamic computed tomographic scans during forced expiration before (left) and after (right) stent implantation. The expiratory collapse of the central airways is effectively prevented by the stent. C, Comparison between a standard dynamic-Y stent (left) and the customized, 3-dimensionally engineered stent (right). D, Bronchoscopy after stent insertion shows a perfect alignment with the mucosa at each level. $L M$, Left main bronchus; $R M$, right main bronchus; $T r$, trachea; $C a$, carina.

Scientific, Marlborough, Mass). Despite an imperfect fit of the anteroposterior diameter and length, the patient reported a subjective improvement. Therefore, the decision was made to offer the patient a custom-made stent. A customized Y-stent analogous to that used in the first case was manufactured. The stent was introduced with rigid forceps and a Kleinsasser laryngoscope, resulting in a perfect alignment with the airways. At the last follow-up 5 months after the stenting procedure, the patient is at home with improved symptoms.

Currently, both patients receive periodic follow-up bronchoscopies, with stent cleansing every 4 to 6 weeks. Mucus clearance is supported by inhalation therapy.

\section{DISCUSSION}

In summary, individually manufactured silicone stents produced with 3D-printing technology led to a significant improvement in the conditions of 2 patients with tracheobronchomalacia and excessive dynamic airway collapse.
Both patients had severe choking attacks, and patient 2 described a constant feeling of an endotracheal foreign body with the off-the-shelf stent. This led to several unplanned hospital admissions. After implantation of the custom-made stents, these symptoms significantly ameliorated. Both patients are satisfied with the stent treatment and their level of symptom control. Conventional silicone stents are usually too small in diameter and length to provide sufficient stabilization in tracheobronchomalacia. This has led to the use of large-diameter custom-made self-expandable metal stents by some centers. ${ }^{3,4}$ However, because of the inherent risks of excessive granulation, stent breaking, and fistulation, metal stents should be avoided for benign indications. With a manufacturing process similar to that reported here, Guibert and colleagues $^{5}$ described the stenting of a complex stenosis 


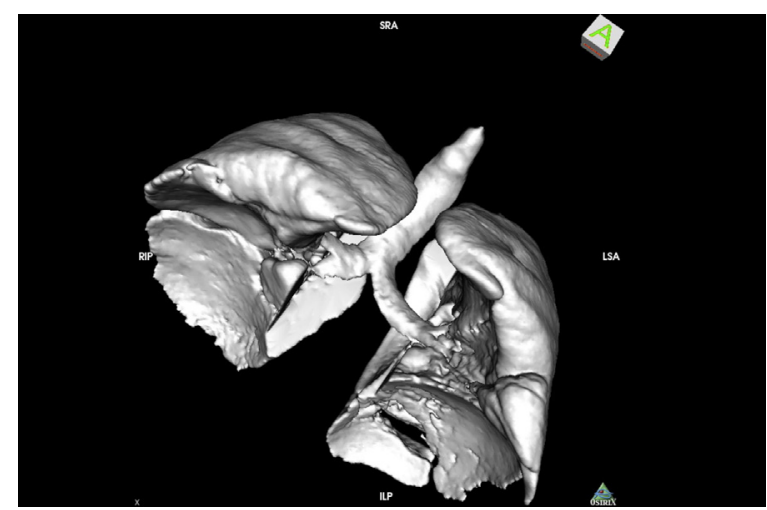

VIDEO 1. Video summary of 3-dimensionally engineered silicone stents. Video available at: https://www.jtcvs.org/article/S0022-5223(18)31794-X/ fulltext.

of the intermediate bronchus in a lung transplant recipient. The treatment of this patient was especially challenging due to severe distortion of the bronchus.

The 2-step process of 3D-printed scaffolds and injection molding allows the production of virtually any stent and at the same time guarantees patient safety by a wellestablished production method. This report of the 2 first patients treated with these novel customized stents demonstrates a proof of principle, which may also have implications for the stent treatment of other airway diseases. In conclusion, the clinical application of this novel type of stent may strongly impact the future of airway stenting, as optimal, rather than best available, solutions can be provided to the individual patient.

We thank Dr Julia Jedamzik for her contribution to the production of the supplementary video.

\section{References}

1. Freitag L, Gördes M, Zarogoulidis P, Darwiche K, Franzen D, Funke F, et al. Towards individualized tracheobronchial stents: technical, practical and legal considerations. Respiration. 2017;94:442-56.

2. Cheng GZ, Folch E, Wilson A, Brik R, Garcia N, San Jose Estepar R, et al. 3D printing and personalized airway stents. Pulmon Ther. 2017;3:59-66.

3. Dutau H, Cavailles A, Fernandez-Navamuel I, Breen DP. Tracheal compression in a patient with Marfan's syndrome-associated tracheomegaly treated by an XXI stent: the largest diameter airway stent ever placed in a previously undescribed airway condition. Respiration. 2009:77:97-101.

4. Pizarro C, Dabir D, Nickenig G, Skowasch D. Nitinol stent insertion in tracheomalacia. Thorax. 2016;71:770-1.

5. Guibert N, Didier A, Moreno B, Mhanna L, Brouchet L, Plat G, et al. Treatment of post-transplant complex airway stenosis with a three-dimensional, computer-assisted customized airway stent. Am J Respir Crit Care Med. 2017;195:e31-3. 